\title{
Optimization of superheated steam treatment conditions for wheat aleurone layer flour
}

\author{
Cancan JIN ${ }^{1 \star}$ (D), Jia GUO ${ }^{1}$, Huixue $\mathrm{ZHU}^{1}$, Jiping WEN ${ }^{1}$
}

\begin{abstract}
Although, wheat aleurone layer flour (WALF) is a good source of nutrients, it has certain disadvantages due relatively high levels of lipids and various of microorganisms and enzymes. Therefore, in the current study, the effect of superheated steam (SS) treatment on stabilization of WALF was investigated. This study aims to explore the effects of SS treatment on the degradation of free fatty acids of WALF under different conditions. The optimal process was obtained by an orthogonal optimization experiment, including optimized SS temperature, material moisture and treatment time. Results showed that the free fatty acids content of WALF significantly were decreased with SS treatment as the increase of treatment temperature, material moisture content and treatment times $(\mathrm{p}<0.05)$. Therefore, the optimum treatment conditions were selected during SS treatment. Compared with raw WALF, the activity of enzymes, total number of microbial colonies and phytate content in WALF were notably reduced after the SS of optimal condition. Nevertheless, its total dietary fiber content, insoluble dietary fiber content, pentosan content, total phenol content and total antioxidant capacity presented a remarkable increase $(\mathrm{p}<0.05)$.
\end{abstract}

Keywords: wheat aleurone layer flour; superheated steam; stabilization; dietary fiber; antioxidant activity.

Practical Application: To degrade the fatty acid value and reduce the enzyme activity as well as the total number of microbial colonies in the wheat aleurone layer flour using superheated steam treatment.

\section{Introduction}

Recently, some epidemiological studies have reported that regular consumption of whole wheat flour and its products is related to reducing the risk of cardiovascular disease, type II diabetes, cancer and other chronic diseases (Meyer et al., 2000). The nutritional benefits of whole wheat flour mainly contain dietary fiber, minerals and phytochemicals, which are primarily existed on the wheat bran and wheat aleurone layer (Manthey \& Schorno, 2002). Wheat aleurone layer is the most nutritious ingredient in wheat grains due to it concentrates major dietary fibers and biologically active compounds, such as proteins, phenolic antioxidants, minerals, phytate, beneficial lipids, and vitamin B and $\mathrm{E}$ etc. (Buri et al., 2004). Some studies have shown that only the addition of $20 \%$ wheat aleurone layer in flour can be equivalent to whole wheat flour in terms of nutrition (Brouns et al., 2012). Besides, the dietary fiber contained in wheat aleurone layer is one of the non-starch polysaccharides and it plays a significant role in manipulating starch based food properties: rheology and textural properties (Mahmood et al., 2018). However, during wheat aleurone layer flour (WALF) storage and produce, its oxidative rancidity is an essential problem, causing a short shelflife. Due to the WALF is close to the outer seed coat of wheat grain, existing high levels of lipids and various of microorganisms and enzymes. Moreover, lipids are easily hydrolyzed by lipase to produce free fatty acids, which can be oxidized by lipoxygenase. This oxidation will result in a poor palatability of WALF and a vain consumption of nutritional properties (Hu et al., 2018). The rancidity processing of lipids can be carried out three steps.
Firstly, triacylglycerols are hydrolyzed by lipase to release free fatty acids (hydrolytic rancidity). The content of free fatty acids is an important indicator for evaluating the hydrolytic rancidity degree of flour (Jiang et al., 2020). Secondly, the released free fatty acids will be oxidized by lipoxygenase or autooxidation to form hydroperoxides (oxidative rancidity). Thirdly, unstable hydroperoxides are degraded to various secondary oxidation products, including carbonyl compounds, hydrocarbons, furans, and other compounds that can cause oxidation rancidity (Lin et al., 2020). Destroying the activity of enzymes is an effective way for preventing lipid degradation in WALF. Therefore, it is necessary to stabilize the WALF.

Superheated steam (SS) is an emerging technology in food processing. Compared with the saturated steam, it has a faster heating rate, lower loss, higher efficiency and safety with no pollution. Thus, SS can better preserve the unstable nutrients in heating process (Wu et al., 2020). Some studies have been reported that SS can be used for drying (Sehrawat et al., 2016), the inactivation of pathogen (Ban et al., 2014) and enzyme (Satou et al., 2010) and sterilization in food industry (Kwon et al., 2018). Meanwhile, there are also some scholars have studied using SS can improve the storage stability of whole wheat flour (Guo et al., 2020), wheat bran (Hu et al., 2018), lightly milled rice (Wu et al., 2014), oats (Head et al., 2009), buckwheat grains (Wang et al., 2020) etc. Recently, a lot of researches on WALF were mainly focused on the separation and extraction of the aleurone layer, the nutritional quality and the improvement of flavor. 
However, there are no relevant reports on the stabilization of WALF. Therefore, in this work, the effects of SS stabilization treatment on the free fatty acid value in WALF was investigated and optimized the treatment parameters of SS by an orthogonal experiment. The inactivation of lipase, lipoxygenase and anti-nutritional factors and the activity of antioxidant also were determined and analyzed. This work aims to provide a theoretical basis for the stabilization of WALF.

\section{Materials and methods}

\subsection{Materials}

The WALF was obtained by Zhishifang Food Technology Co., Ltd., Shandong, China. The WALF components were analyzed according to the Chinese National Standards methods, was 8.19\% moisture (GB 5009.3-2016), 4.23\% ash (GB 5009.4-2016), $3.62 \%$ fat (GB 5009.6-2016), 18.63\% protein (GB 5009.5-2016), $33.13 \%$ starch (GB 5009.9-2016), 28.13\% total dietary fiber (GB 5009.88-2014), Other accounts for 4.07\%. All chemical reagents used were of analytical grade.

\subsection{SS processing}

WALF was processed using SS sterilization equipment (Lab homemade, Henan, China) with steam velocity of $3 \mathrm{~m} / \mathrm{s}$. Sample (60 g of WALF) was removed and placed on a 240-mesh sieve and make it evenly distributed. The test can be divided into three groups. Firstly, the WALF was adjusted to the target moisture content $(12 \%, 14 \%, 16 \%, 18 \%, 20 \%, 22 \%, 24 \%, 26 \%)$ and homogenize for a period of 24 hours before the SS treatment, then treated them for 3 minutes at a steam temperature of $210^{\circ} \mathrm{C}$. In the second set of trials, the WALF with a moisture content of $20 \%$ was put into a feed system that was treated with a steam temperature of $210^{\circ} \mathrm{C}$, and the processing time was $1,2,3,4$, and $5 \mathrm{~min}$, respectively. In the third set of experiments, the WALF with a moisture content of $20 \%$ was placed and treated 3 minutes for six steam temperatures with 150, 170, 190, 210, 230 and $250^{\circ} \mathrm{C}$, respectively. Then removed the processed samples in a tray, and passed them through a 60 -mesh $(<250 \mu \mathrm{m})$ sieve after cooling to room temperature.

\subsection{Determination of FFA content}

The FFA content in WALF was measured by titration according to the method of the Chinese National Standard method (GB/T 5510-2011). The FFA content (mg/100 g) was calculated according to Formula 1.

$\mathrm{FFA}=\frac{(\mathrm{V} 1-\mathrm{V} 0) \times \mathrm{c} \times 56.1 \times 2 \times 100}{\mathrm{~m} \times(100-\mathrm{w})} \times 100$

where $\mathrm{V}_{1}=$ volume of sample titration $(\mathrm{mL}), \mathrm{V}_{0}$ = volume of blank titration $(\mathrm{mL}), \mathrm{c}=$ normality of titrant $(\mathrm{mol} / \mathrm{L}), \mathrm{m}=$ weight of sample $(\mathrm{g})$, and $\mathrm{w}=$ moisture of sample (\%).

\subsection{Chemical-physical analysis under the optimal processing conditions}

\section{Enzyme activity assay}

The lipase (LA) activity in WALF was measured following the method suggested by the Chinese National Standard (GB/T 5523-2008). Sample (2 g WALF) was placed into a mortar containing a small amount of quartz sand and $1 \mathrm{~mL}$ pure grease, added $5 \mathrm{~mL}$ buffer solution and made it well, then transferred it to a stoppered conical flask and incubated it subsequently at $30{ }^{\circ} \mathrm{C}$ for $24 \mathrm{~h}$ in an incubator (SPX-150B-Z, Boxun Industrial Co., Ltd. Medical Equipment Factory, Shanghai, China). Taking it out, added $50 \mathrm{~mL}$ of ethanol and ether mixture, shaking and standing for 1-2 min to filter, added 3-5 drops of phenolphthalein indicator to $25 \mathrm{~mL}$ of filtrate, and titrated with $0.05 \mathrm{~mol} / \mathrm{L} \mathrm{KOH}$ titrant. Took another $2 \mathrm{~g}$ sample as a control and the operation was same as above except that it was not kept at $30{ }^{\circ} \mathrm{C}$ for $24 \mathrm{~h}$. The LA activity (mg/g) was calculated according to the Formula 2.

$\mathrm{X}(\mathrm{mg} / \mathrm{g})=\frac{(\mathrm{V} 1-\mathrm{V} 0) \times \mathrm{c} \times 56.1}{\mathrm{~m} \times(100-\mathrm{M})} \times \frac{60}{25} \times 100$

where $\mathrm{X}=\mathrm{LA}$ activity $(\mathrm{mg} / \mathrm{g}), \mathrm{V}_{1}=$ volume of sample titration $(\mathrm{mL}), \mathrm{V}_{0}=$ volume of blank titration $(\mathrm{mL}), \mathrm{c}=$ normality of titrant $(\mathrm{mol} / \mathrm{L}), \mathrm{m}=$ weight of sample $(\mathrm{g})$, and $\mathrm{M}=$ moisture of sample (\%).

Lipoxygenase (LOX) activity in WALF was measured as described Shi (2005). Sample (1 g WALF) was incubated in $200 \mathrm{~mL}$ of phosphate buffer solution (0.01M, pH7.0) and shook it at room-temperature for $1 \mathrm{~h}$. The mixture was centrifuged at 3,500 rpm for $15 \mathrm{~min}$ in a centrifuge (LXJ-IIB, Anting Scientific Instrument Factory, Shanghai, China). An aliquot of supernatant that contained crude LOX extract was placed in crushed ice. Substrate preparation: Dispersed $0.25 \mathrm{~mL}$ of Tween 20 in $10 \mathrm{~mL}$ of boric acid buffer (0.2 M, pH 9.0), added $0.27 \mathrm{~mL}$ of linoleic acid dropwise with shaking, and mixed it well to disperse the linoleic acid as a fine emulsion in the liquid. Added $1.0 \mathrm{~mL}$ of $1 \mathrm{~mol} / \mathrm{L}$ $\mathrm{NaOH}$ solution, and adjusted the $\mathrm{pH}$ to 9.0 with concentrated hydrochloric acid. Then dilute the mixture to $500 \mathrm{~mL}$ with the above boric acid solution. A solution containing $0.2 \mathrm{~mL}$ crude enzyme extract and $0.8 \mathrm{~mL}$ substrate solution $(0.1 \mathrm{M})$ were placed in a quartz cuvette and stopped the reaction with anhydrous ethanol solution. Absorbance of the solution was recorded at $234 \mathrm{~nm}$ with an UV-visible spectrophotometer (UV2150/2150, Ronnik Instrument Co., Ltd., Shanghai, China).

\section{Microbial analysis}

Sample (25 g WALF) was removed and placed into $225 \mathrm{~mL}$ $0.85 \%$ aseptic physiological saline (PA), and the mixture was homogenized using a magnetic stirring apparatus (HJ-6, Jintan District Xicheng Xinrui Instrument Factory, China) for $60 \mathrm{~min}$. A series of tenfold dilutions was made using PA, and $1 \mathrm{~mL}$ of the appropriate dilutions was poured onto sterile plate count agar plates to determine the total plate count. The plates were then incubated at $36 \pm 1{ }^{\circ} \mathrm{C}$ for $48 \pm 2 \mathrm{~h}$ (GB 4789.2-2016).

\section{Phytate content assay}

Phytate content in WALF was measured according to the method of Buddrick et al. (2014).

\section{Determination of TDF, SDF and IDF}

Total dietary fiber (TDF), soluble dietary fiber (SDF) and insoluble dietary fiber (IDF) content in WALF were measured respectively following the method suggested by the method of the Chinese National Standard method (GB 5009.88-2014). 


\section{Determination of pentosan content}

Pentosan content in WALF was measured as described by Douglas (1981).

\section{Determination of total phenol content}

Total phenol content (TPC) in WALF was measured according to the method of Xue (2017). Standard curve drawing: 0.01g gallic acid was dissolved in $50 \mathrm{~mL} 80 \%$ ethanol solution and diluted to $100 \mathrm{~mL}$ to obtain a stock solution with a mass concentration of $1000 \mathrm{mg} / \mathrm{L}$. Pipetted the stock solution 0, 0.125, 0.25, 0.5, $1.0 \mathrm{~mL}$ in a $10 \mathrm{~mL}$ volumetric flask, with $80 \%$ ethanol solution diluted to $10 \mathrm{~mL}$ respectively. Determination of samples: sample (1 g WALF) was incubated in $30 \mathrm{~mL} \mathrm{80 \%} \mathrm{ethanol,} \mathrm{extracted}$ with ultrasonic (KQ-500DE, Ultrasonic Instrument Co., Ltd., Kunshan, China) at $40^{\circ} \mathrm{C}$ for $30 \mathrm{~min}$, and filter. Took $2 \mathrm{~mL}$ of the filtrate/standard solution into a colorimetric tube, added $3 \mathrm{~mL}$ of Folin's reagent respectively, shook it well and allowed it react for $5 \mathrm{~min}$, then added $8 \mathrm{~mL}$ of $10 \% \mathrm{NaCO}_{3}$, and sealed it in a $30{ }^{\circ} \mathrm{C}$ shaker (THZ-82A, Jielong Technology Co., Ltd., Henan, China) in a water bath for $2 \mathrm{~h}$ and measured the absorbance at $740 \mathrm{~nm}$.

\section{Determination of total antioxidant activity}

The total antioxidant activity of WALF was determined according to the instructions of the total antioxidant capacity test kit provided by Jiancheng Institute of Bioengineering (Nanjing, China).

\section{Water holding capacity and expansion force analysis}

Water holding capacity and expansion force of WALF were measured as described (Li et al., 2011) and some details had been slightly modified.

Sample (1 g WALF) was removed into a centrifuge cup containing $50 \mathrm{~mL}$ of distilled water, stirred it magnetically at room temperature for $0.5 \mathrm{~h}$ and centrifuged it at $3000 \mathrm{r} / \mathrm{min}$ for $20 \mathrm{~min}$, then discard the supernatant and weigh the residue (Formula 3).

Water holding capacity $(\mathrm{g} / \mathrm{g})=\frac{\mathrm{ml}-\mathrm{m}}{\mathrm{m}}$

where $\mathrm{m}_{1}=$ residue weight $(\mathrm{g}), \mathrm{m}=$ weight of sample $(\mathrm{g})$.

Sample (1 g WALF) was removed into a graduated glass tube to record the dry volume of the sample, added $10 \mathrm{~mL}$ distilled water, recorded the wet base volume of the sample after standing for 12 hours at room temperature (Formula 4).

Expansion force $(\mathrm{mL} / \mathrm{g})=\frac{\mathrm{V} 1-\mathrm{V}}{\mathrm{m}}$

where $\mathrm{V}_{1}=$ The volume of the sample after expansion $(\mathrm{mL})$, $\mathrm{V}=$ Dry volume of sample $(\mathrm{mL}), \mathrm{m}=$ the weight of sample $(\mathrm{g})$.

\section{Determination the color difference of sample}

The color $\left(L^{*}, a^{*}, b^{*}\right)$ of WALF were measured using a Chromameter (SMY2000, Shengmingyang Technology Development Co., Ltd., Beijing, China).

\subsection{Statistical analysis}

Each experiment was repeated at least three times. All data were presented as mean \pm standard deviation (SD) and analyzed by using the SPSS 25 software. Analysis of variances (ANOVA) was conducted at $95 \%$ confidence level and differences among means were detected with Duncan's test. Graphs were made by the origin 9.5 software.

\section{Results and discussion}

\subsection{Effect of single factors test on the FFA content in WALF}

\section{SS temperature}

The FFA content in WALF with different SS temperatures was presented in Figure 1. As shown in Figure 1, the FFA content was significantly decreased with the increase of SS temperatures $(p<0.05)$, which was due to the productions of fatty acids from lipid oxidation were thermally instability, and easily formed isomerization or a degradation with high temperature (Shin et al., 2012). As the SS temperature was increased, the color of WALF gradually deepened. Specifically, when the temperature was $230^{\circ} \mathrm{C}$, the WALF has been slightly scorched, then it appeared severely scorching phenomenon at $250{ }^{\circ} \mathrm{C}$. While the FFA content was lower and no scorching occurred at $210^{\circ} \mathrm{C}$, the SS treatment temperature of $210 \sim 230{ }^{\circ} \mathrm{C}$ was selected among different temperatures.

\section{Processing time}

As shown in Figure 2, with the extension of SS treatment times, the FFA content in WALF appeared a remarkable decrease $(p<0.05)$. The thermodynamic process of SS treatment on samples can be divided into three stages. In the first stage, in the short time of SS treatment, some steams were initial condensed on the surface of materials, meanwhile, released a large number of thermal energy, rising rapidly the surface temperature of samples. In the second stage, with the extension of the treatment

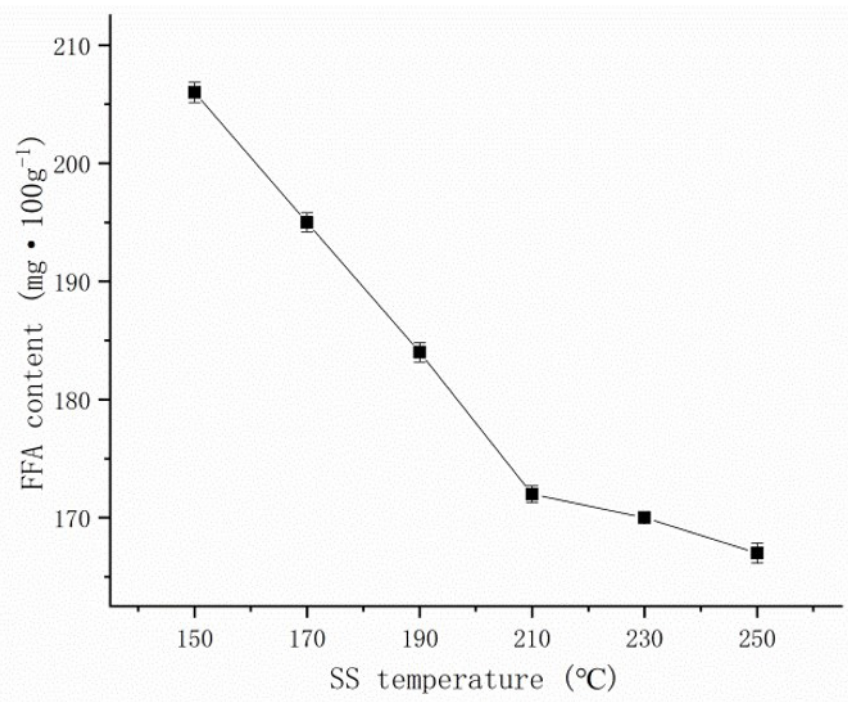

Figure 1. The effect of SS temperatures on FFA content. 


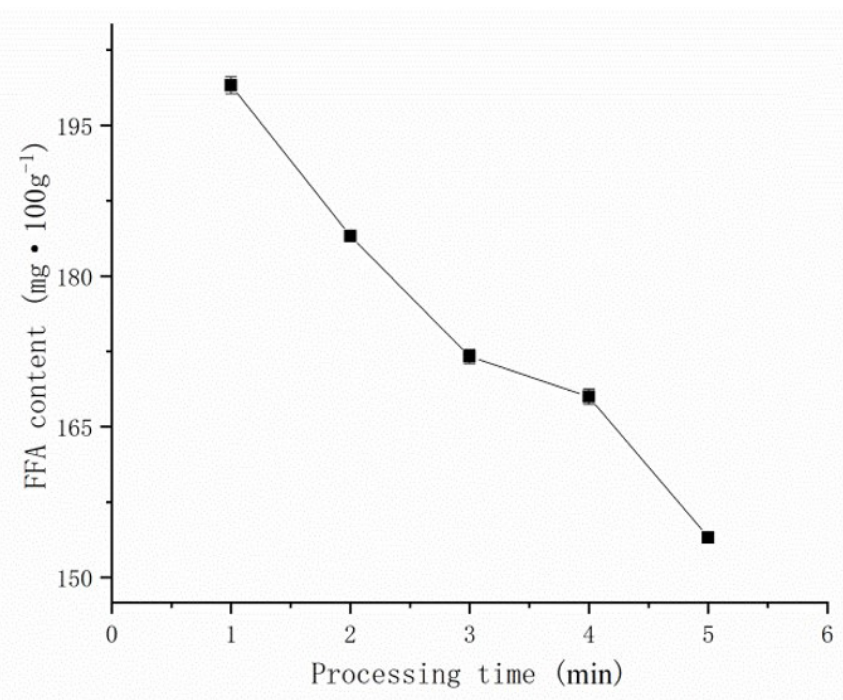

Figure 2. The effect of processing time on FFA content.

times, when the surface temperature of samples was reached the boiling point of water, the condensed water began to evaporate on surface. In the third stage, the temperature would continue to rise with the extension of the treatment time, and the moisture inside the sample also evaporated then removed with the superheated steam $(\mathrm{Hu}, 2018)$. Therefore, as the prolongation of the treatment times, the more treatment temperature of the WALF, the better the degradation effect on the FFA content. It can be seen that the FFA content in WALF presented a slightly decrease with the treatment time extended from 3 to $4 \mathrm{~min}$. However, its FFA contents was significantly decreased when the treatment time was $5 \mathrm{~min}(\mathrm{p}<0.05)$, but the material has already burnt under this condition. Comprehensive consideration of SS processing time of 3 4 min might be an optimum parameter.

\section{Material moisture}

The FFA content in WALF with different material moistures was presented in Figure 3. As seen in Figure 3, there was no significant difference in FFA content when the material moisture content reached $14 \%$ to $16 \%$. Subsequently, the FFA content decreased sharply with the increase of material moisture content, which might be due to the moisture have reached the boiling point and began to vaporize when the processing time was 3 minutes $(\mathrm{p}<0.05)$. In a closed processing chamber, the more moisture content of the samples at the same temperature, the more steam has been produced and formed a bigger air pressure. As a result, the effect of degrading FFA was achieved under the action of high temperature and pressure. As moisture increasing, the FFA content showed a reduction and the downward trend was relatively flat between $22 \%, 24 \%$ and $26 \%$. This study did not try to a higher moisture content because the long-term process of homogenization after adjusting the moisture content before SS treatment was considered. Among which the higher the moisture content, the more favorable the activity of lipase and lipoxygenase (Håkansson \& Jägerstad, 1990). Therefore, the

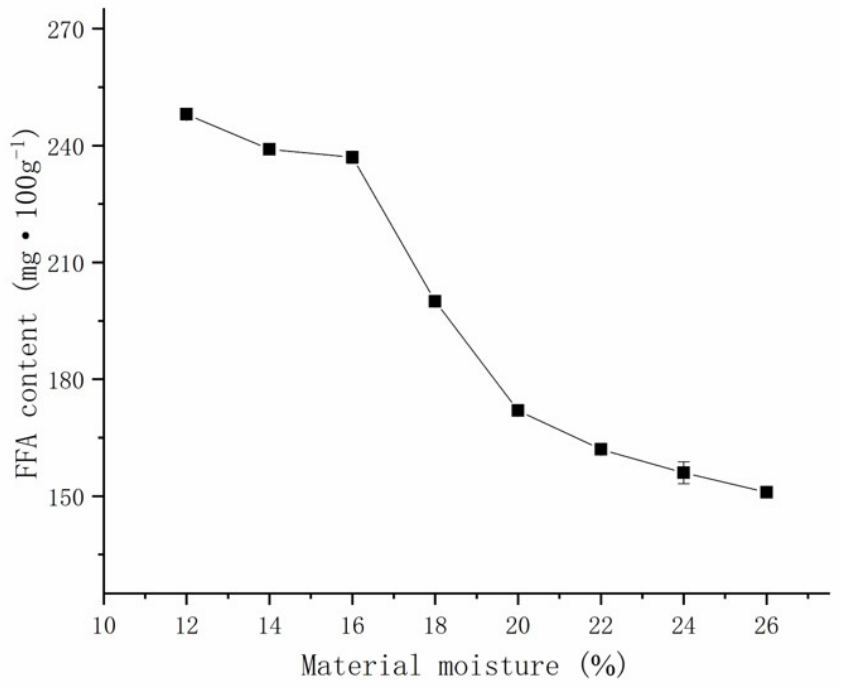

Figure 3. The influence of material moistures on FFA content.

moisture content of the WALF was 22 24\% in comprehensive consideration.

\subsection{Orthogonal design and result analysis of SS treatment conditions}

An orthogonal $\mathrm{L}_{9}\left(3^{4}\right)$ test design was used to investigate the optimal SS treatment condition of the degradation of FFA in WALF. As seen in Table 1, the experiment was carried out with 3 factors and 3 levels, namely SS temperature (190, 210, $\left.230^{\circ} \mathrm{C}\right)$, material moisture $(20,22,24 \%)$, and processing time $(2,3,4 \mathrm{~min})$. The range of each factor level was based on the results of preliminary experiments. The FFA content was the dependent variable. Orthogonal experiment results for optimal SS treatment condition of the degradation of FFA in WALF. Range $\mathrm{B}>$ Range $\mathrm{C}>$ Range A (Table 1) indicated that the most important influence factor on the degradation effect of FFA in WALF was material moisture content, followed by processing time and SS temperature. The range of null column was 0.666 , which meant that accidental error was small and experimental result was reliable. The FFA content reflects the rancidity of the sample, so take the minimum value in the test results. Therefore, by comparing $\mathrm{k}_{1}, \mathrm{k}_{2}$ and $\mathrm{k}_{3}$ values of three factors, the best combination was determined as $\mathrm{B}_{3} \mathrm{C}_{3} \mathrm{~A}_{2}$, revealing that the optimal SS treatment conditions for material moisture of $24 \%$, processing time of $4 \mathrm{~min}$ and SS temperature of $210^{\circ} \mathrm{C}$. During treatment, the SS temperature, material moisture, and processing time had a synergistic effect on the degradation of FFA. The moisture in the material gradually reached the boiling point with the increasing of SS temperature to form steam and generated a certain pressure in the closed processing chamber. The fatty acids were thermally instability and easily formed isomerization and degradated in the high temperature and pressure environment. Doubtlessly, the extension of processing time would facilitate the reaction process. As a result, the FFA content in WALF was $127 \mathrm{mg} / 100 \mathrm{~g}$ under this condition and the degradation rate was 
Table 1. The levels of orthogonal tests and results.

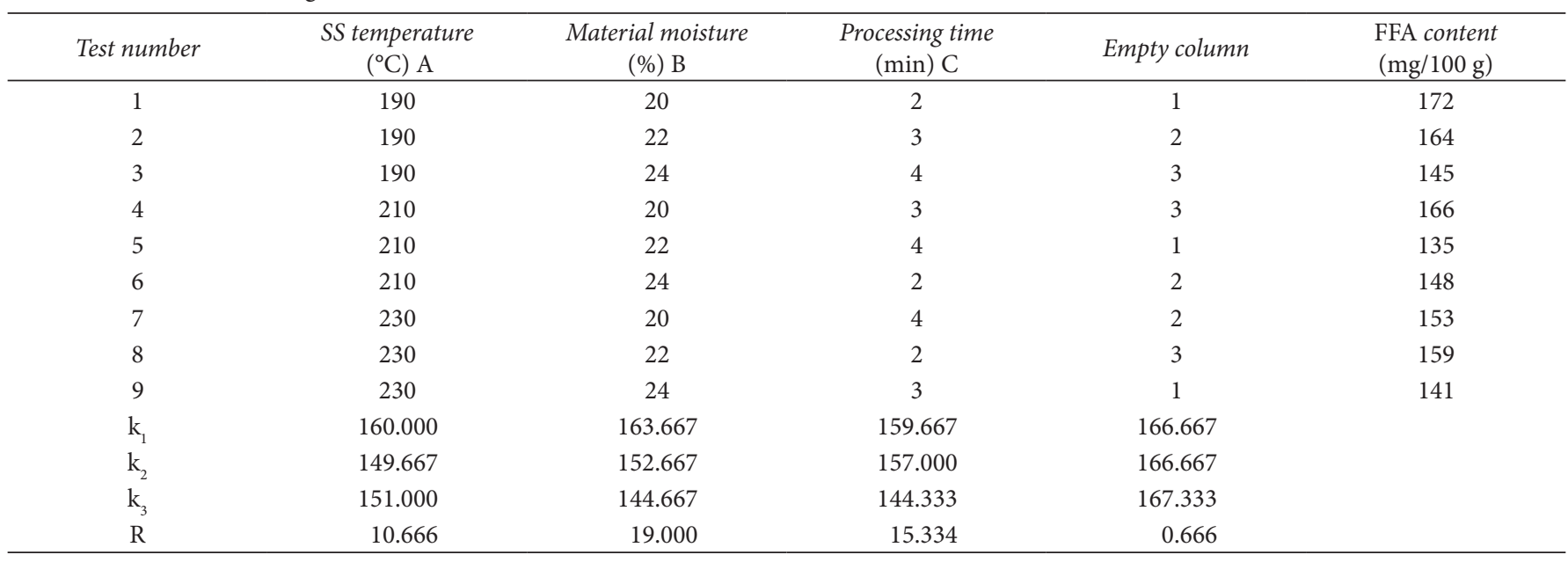

greater than the result of test $A_{2} B_{1} C_{2}$. Therefore, $A_{2} B_{3} C_{3}$ could be used as the best solution.

\subsection{Enzyme activities and total plate count in WALF}

The lipase and lipoxygenase activities, total plate count in WALF under the optimal condition and the control group were shown in Table 2. After SS treatment at $210{ }^{\circ} \mathrm{C}$ for $4 \mathrm{~min}$, the activities of lipase and lipoxygenase decreased by $89.33 \%$ and $76.71 \%$ respectively. Lipase and lipoxygenase activities decreased sharply after SS treatment $(\mathrm{p}<0.05)$. This was consistent with the findings of Guo et al. (2020). The decrease of lipase activity was more apparent than lipoxygenase in the treatment. However, Xu et al. (2016) treated wheat germ with water bath and microwave irradiation treatment found that lipase is more heat-stable than lipoxygenase when heat-treating. Therefore, the heat resistance of lipase and lipoxygenase may differ with heat treatment methods and treatment times. The reason why the enzyme activity of lipase and lipoxygenase reduced significantly might be the essence of lipase and lipoxygenase is protein. The high temperature destroyed the hydrogen bond, van der Waals force, hydrophobic bond, etc. in the protein molecule, which has resulted in protein denaturation achieved the purpose of inactivating enzyme activity.

The initial bacteria quantity in WALF was $4.44 \log _{10} \mathrm{CFU} / \mathrm{g}$. Then the total plate count reduced below $3.80 \log _{10} \mathrm{CFU} / \mathrm{g}$ after the SS optimal condition processing. The reason why the total number of microbial colonies in the WALF decreased significantly $(\mathrm{p}<0.05)$ might be due to most of the microorganisms were difficult to survive when the sample was exposed to a high temperature of $210{ }^{\circ} \mathrm{C}$. Hu et al. (2016) also found that the number of bacteria decreased sharply when wheat grain kernel was processed with SS at $200{ }^{\circ} \mathrm{C}$. In short, SS treatment improves the storage and edible safety of WALF.

\subsection{Effect of SS treatment on the nutritional components in the WALF}

Phytate is an anti-nutritional factor. Its anti-nutritional effect is derived from its strong binding ability to mineral cations such as iron, magnesium, zinc and calcium, resulting in changing
Table 2. Enzyme activities and total plate count in WALF.

\begin{tabular}{cccc}
\hline Sample & LA $(\mathrm{mg} / \mathrm{g})$ & LOX $(\%)$ & $\begin{array}{c}\text { total plate count } \\
\left(\log _{10} \text { CFU/g) }\right.\end{array}$ \\
\hline Control & $435.2 \pm 0.4^{\mathrm{a}}$ & $100.00 \pm 0.00^{\mathrm{a}}$ & $4.44 \pm 0.04^{\mathrm{a}}$ \\
SS processed & $46.4 \pm 0.9^{\mathrm{b}}$ & $23.29 \pm 0.77^{\mathrm{b}}$ & $3.80 \pm 0.02^{\mathrm{b}}$ \\
\hline
\end{tabular}

Means values with unlike letters in the same column are significantly different $(p<0.05)$.

their solubility, functionality, absorption and digestibility, which will affect the body's absorption of desirable nutrients and thereby reducing the nutritional value of the end product (Buddrick et al., 2014). As shown in Table 3, phytate level was lower than the control group after SS treatment. It was reduced from the initial $24.76 \mathrm{mg} / \mathrm{g}$ to $16.43 \mathrm{mg} / \mathrm{g}$, which was a $33.64 \%$ reduction. This was because phytate lost its stability rapidly at a high temperature and began to decompose violently into low phosphates and phosphate inositol esters (Wu et al., 2020). In addition, other substances in WALF perhaps decomposed at high temperature to produce an acidic environment that promoted the hydrolysis of phytate.

Dietary fibers are mainly polysaccharides present on the outermost cell wall which can promote intestinal peristalsis and play an important role in preventing chronic diseases such as colon cancer and cardiovascular disease. At the molecular level, dietary fiber and other bioactive compounds are mainly present in bound forms, not as free constituents (Rosa-Sibakov et al., 2015). As shown in Table 3, compared with the control sample, the total dietary fiber (TDF) and insoluble dietary fiber (IDF) content in WALF increased significantly, while the content of soluble dietary fiber (SDF) notably reduced after SS treatment $(\mathrm{p}<0.05)$. The reason might be that the main components of SDF are glucan, xylose, arabinose, galactose and mannose. The glucan in SDF degraded and turned it into small molecular substances with a degree of polymerization below 12 at a high temperature during SS processing (Zhang et al., 2020). The increase of TDF and IDF content was related to the softening and cleavage of the fibers in the WALF after SS treatment, which led to the break of the intermolecular covalent bonds and changed the 
Table 3. Comparison of nutritional quality in WALF

\begin{tabular}{cccccccc}
\hline Sample & $\begin{array}{c}\text { Phytate } \\
(\mathrm{mg} / \mathrm{g})\end{array}$ & $\begin{array}{c}\text { TDF } \\
(\mathrm{g} / 100 \mathrm{~g})\end{array}$ & $\begin{array}{c}\text { SDF } \\
(\mathrm{g} / 100 \mathrm{~g})\end{array}$ & $\begin{array}{c}\text { IDF } \\
(\mathrm{g} / 100 \mathrm{~g})\end{array}$ & $\begin{array}{c}\text { Pentosan } \\
(\mathrm{g} / 100 \mathrm{~g})\end{array}$ & $\begin{array}{c}\text { Total phenols } \\
(\mathrm{mg} / \mathrm{g})\end{array}$ & $\begin{array}{c}\text { Total antioxidant value } \\
(\mathrm{mmol} / 100 \mathrm{~g})\end{array}$ \\
\hline Control & $24.76 \pm 0.34^{\mathrm{a}}$ & $28.10 \pm 0.05^{\mathrm{a}}$ & $3.66 \pm 0.01^{\mathrm{a}}$ & $24.43 \pm 0.05^{\mathrm{a}}$ & $10.23 \pm 0.01^{\mathrm{a}}$ & $1.53 \pm 0.00^{\mathrm{a}}$ & $0.2292 \pm 0.0030^{\mathrm{a}}$ \\
SS processed & $16.43 \pm 0.34^{\mathrm{b}}$ & $28.98 \pm 0.02^{\mathrm{b}}$ & $3.30 \pm 0.04^{\mathrm{b}}$ & $25.68 \pm 0.02^{\mathrm{b}}$ & $10.63 \pm 0.02^{\mathrm{b}}$ & $1.62 \pm 0.00^{\mathrm{b}}$ & $0.4890 \pm 0.0023^{\mathrm{b}}$ \\
\hline
\end{tabular}

Means values with unlike letters in the same column are significantly different $(\mathrm{p}<0.05)$.

molecular polarity of aleurone cell. It might also be caused by the conversion of starch in the sample into resistant starch in a humid and hot environment (Chung et al., 2008). As shown in Table 3 , the pentosan level was significantly higher than the raw WALF after SS treatment $(\mathrm{p}<0.05)$ which might due to the lignocellulose structure in the aleurone cell wall has been softened during SS treatment processing and thereby increasing the solubility of pentosan (Luo et al., 2013).

Phenolics are compounds possessing one or more aromatic rings with one or more hydroxyl groups and generally are categorized as phenolic acids, flavonoids, stilbenes, coumarins, and tannins (Liu, 2004). The phenolic compounds in our diet may also provide health benefits associated with reducing the risk of chronic diseases (Liu, 2007). The phenolic compounds in wheat mainly exist in the wheat aleurone layer, peel and cell wall, and only a trace amount exists in the endosperm (Smith \& Hartley, 1983). The total phenol content (TPC) in WALF after SS treatment increased compared with the control group, which may be due to phenolic acids are mainly present in the bound form, linked to cell wall structural components such as cellulose, lignin, and proteins through ester bonds (Liu, 2007). However, the ester bond might be break at a high temperature, causing the bound phenolic acid to be released in the process of SS treatment, which was consistent with the research of Zhang et al. (2019). Dewanto pointed out that thermal processing will help to release these bound phenolic acids (Dewanto et al., 2002).

Antioxidant capacity is an important feature that evaluates the nutritional and processing quality of wheat components. Mateo Anson et al. (2008) indicated that the antioxidant potency of wheat grain fractions is predominantly determined by aleurone content, which can be attributed to the presence of relatively large amounts of phenolic compounds, primarily ferulic acid. Phenolic compounds in whole grains have the ability to scavenge free radicals, which contributes to antioxidant activity. Liyana-Pathirana \& Shahidi (2006) concluded that total phenol content was positively correlated with antioxidant capacity. It could be seen from Table 3 that the increase of total antioxidant value might be related to the increase of total phenol content, which was consistent with the results of Wu et al. (2016).

\subsection{The influence of SS treatment on the water holding capacity, expansion force and color of WALF}

As shown in Table 4, the water holding capacity and expansion capacity of WALF increased by $24.43 \%$ and $33.33 \%$ respectively after SS treatment. The reason might be that the pressure between the inside and outside of the wheat aleurone cell exceeded the bearing capacity of the cell wall during the treatment process, causing the surface of cell wall to rupture into an irregular shape. As a result, the fiber became loose and porous and thereby the
Table 4. water holding capacity, expansion force and color of native WALF and SS-WALF.

\begin{tabular}{cccccc}
\hline Sample & $\begin{array}{c}\text { water } \\
\text { holding } \\
\text { capacity } \\
(\mathrm{g} / \mathrm{g})\end{array}$ & $\begin{array}{c}\text { expansion } \\
\text { capacity } \\
(\mathrm{mL} / \mathrm{g})\end{array}$ & $\mathrm{L}^{*}$ & $\mathrm{a}^{*}$ & $\mathrm{~b}^{*}$ \\
\hline Control & $2.21 \pm 0.03^{\mathrm{a}}$ & $1.20 \pm 0.14^{\mathrm{a}}$ & $77.43 \pm 0.12^{\mathrm{a}}$ & $0.56 \pm 0.04^{\mathrm{a}}$ & $14.98 \pm 0.13^{\mathrm{a}}$ \\
$\mathrm{SS}$ & $2.75 \pm 0.10^{\mathrm{b}}$ & $1.60 \pm 0.00^{\mathrm{b}}$ & $69.03 \pm 0.11^{\mathrm{b}}$ & $2.92 \pm 0.06^{\mathrm{b}}$ & $20.90 \pm 0.08^{\mathrm{b}}$ \\
processed
\end{tabular}

water holding capacity and expansion capacity of WALF were significantly increased $(p<0.05)$. Since both dietary fiber and pentosan all have a high hydrophilicity, the increase in TDF, IDF and pentosan content might also be the reason for the increase in water holding capacity and swelling capacity.

Flour color is one of the quality factors for processed flour. Heat treatment can cause color change in the grain (Guo et al., 2020). From Table 4, compared with the control group, the $\mathrm{L}^{*}$ value of WALF significantly decreased $(p<0.05)$ (from 77.43 to 69.03 ) and $\mathrm{a}^{\star}$ and $\mathrm{b}^{\star}$ values significantly increased $(\mathrm{p}<0.05)$ (from 0.56 and 14.98 to 2.92 and 20.90 , respectively) after SS processing. This indicated that the color of SS-WALF was darker, more red and yellow than that of native WALF. The caramelization and Maillard reaction during high temperature and long time processing should be responsible for the phenomenon (Hu et al., 2017).

\section{Conclusions}

Through single factor experiments, material moisture, processing time and SS temperature were identified as significantly influencing factors on the degradation effect of FFA in WALF. Based on orthogonal experiments, the optimum conditions were selected during SS processing, which were the SS temperature of $210^{\circ} \mathrm{C}$, the material moisture content of $24 \%$ and the treatment time of $4 \mathrm{~min}$. Under this treatment condition, compared with native WALF, SS-WALF exhibited lower FFA value, lipase and lipoxygenase activities, phytate content and total number of microbial colonies as well as a higher dietary fiber content, comparable or higher extractable phenolic compounds contents and stronger antioxidant activities. In addition, the water holding capacity and expansion capacity were also increased. Accordingly, SS processing should be a novel and effective technology that could stabilize WALF while maintain/improve its nutritional attributes at the same time. It will provide the possibility for the application of WALF in food.

\section{Acknowledgements}

This work was financed by the National Key Research and Development Program of China (No. 2018YFD0401001). 


\section{References}

Ban, G. H., Yoon, H., \& Kang, D. H. (2014). A comparison of saturated steam and superheated steam for inactivation of Escherichia coli o157:h7, Salmonella Typhimurium, and Listeria monocytogenes biofilms on polyvinyl chloride and stainless steel. Food Control, 40, 344-350. http://dx.doi.org/10.1016/j.foodcont.2013.12.017.

Brouns, F., Hemery, Y., Price, R., \& Anson, N. M. (2012). Wheat aleurone: separation, composition, health aspects, and potential food use. Critical Reviews in Food Science and Nutrition, 52(6), 553-568. http://dx.doi.org/10.1080/10408398.2011.589540. PMid:22452734.

Buddrick, O., Jones, O. A. H., Cornell, H. J., \& Small, D. M. (2014). The influence of fermentation processes and cereal grains in wholegrain bread on reducing phytate content. Journal of Cereal Science, 59(1), 3-8. http://dx.doi.org/10.1016/j.jcs.2013.11.006.

Buri, R. C., Reding, W. V., \& Gavin, M. H. (2004). Description and characterization of wheat aleurone. Cereal Foods World, 49(5), 274-282.

Chung, H., Liu, Q., \& Hoover, R. (2008). Impact of annealing and heat-moisture treatment on rapidly digestible, slowly digestible and resistant starch levels in native and gelatinized corn, pea and lentil starches. Carbohydrate Polymers, 75(3), 436-447. http://dx.doi. org/10.1016/j.carbpol.2008.08.006.

Dewanto, V., Wu, X., \& Liu, R. H. (2002). Processed sweet corn has higher antioxidant activity. Journal of Agricultural and Food Chemistry, 50(17), 4959-4964. http://dx.doi.org/10.1021/jf0255937. PMid:12166989.

Douglas, S. G. (1981). A rapid method for the determination of pentosans in wheat flour. Food Chemistry, 7(2), 139-145. http:// dx.doi.org/10.1016/0308-8146(81)90059-5.

Guo, X. N., Wu, S. H., \& Zhu, K. X. (2020). Effect of superheated steam treatment on quality characteristics of whole wheat flour and storage stability of semi-dried whole wheat noodle. Food Chemistry, 322, 126738. http://dx.doi.org/10.1016/j.foodchem.2020.126738. PMid:32283361.

Håkansson, B., \& Jägerstad, M. (1990). The effect of thermal inactivation of lipoxygenase on the stability of vitamin E in wheat. Journal of Cereal Science, 12(2), 177-185. http://dx.doi.org/10.1016/S07335210(09)80099-4.

Head, D. S., Cenkowski, S., Arntfield, S., \& Henderson, K. (2009). Superheated steam processing of oat groats [J]. LebensmittelWissenschaft + Technologie, 43(4), 690-694. http://dx.doi.org/10.1016/j. lwt.2009.12.002.

$\mathrm{Hu}, \mathrm{Y} . \mathrm{M}$. (2018). Effect of superheated steam treatment on qualities of wheat and wheat flour. Beijing: China Agricultural University. (in Chinese).

Hu, Y. M., Nie, W., Hu, X. Z., \& Li, Z. G. (2016). Microbial decontamination of wheat grain with superheated steam. Food Control, 62, 264-269. http://dx.doi.org/10.1016/j.foodcont.2015.11.001.

Hu, Y., Wang, L., \& Li, Z. (2018). Superheated steam treatment on wheat bran: enzymes inactivation and nutritional attributes retention. Lebensmittel-Wissenschaft + Technologie, 91, 446-452. http://dx.doi. org/10.1016/j.lwt.2018.01.086.

Hu, Y., Wang, L., Zhu, H., \& Li, Z. (2017). Superheated steam treatment improved flour qualities of wheat in suitable conditions. Journal of Food Processing and Preservation, 41(6), e13238. http://dx.doi. org/10.1111/jfpp.13238.

Jiang, H., Liu, T., \& Chen, Q. S. (2020). Quantitative detection of fatty acid value during storage of wheat flour based on a portable nearinfrared (NIR) spectroscopy system. Infrared Physics \& Technology, 109, 109. http://dx.doi.org/10.1016/j.infrared.2020.103423.
Kwon, S. A., Song, W. J., \& Kang, D. H. (2018). Comparison of the effect of saturated and superheated steam on the inactivation of Escherichia coli O157:H7, Salmonella Typhimurium and Listeria monocytogenes on cantaloupe and watermelon surfaces. Food Microbiology, 72, 157 165. http://dx.doi.org/10.1016/j.fm.2017.10.012. PMid:29407392.

Li, M. Q., Wang, Y., \& Zhao, Y. (2011). Optimization on treatment by ultra-high-pressure to wheat bran and its microstructure observation with SEM. Food and Machinery, 27(4), 10-14.

Lin, D., Long, X., Huang, Y., Yang, Y., Wu, Z., Chen, H., Zhang, Q., Wu, D., Qin, W., \& Tu, Z. (2020). Effects of microbial fermentation and microwave treatment on the composition, structural characteristics, and functional properties of modified okara dietary fiber. $L W T, 123$, 109059. http://dx.doi.org/10.1016/j.lwt.2020.109059.

Liu, R. H. (2004). Potential synergy of phytochemicals in cancer prevention: mechanism of action. The Journal of Nutrition, 134(12, Suppl.), 3479S-3485S. http://dx.doi.org/10.1093/jn/134.12.3479S. PMid:15570057.

Liu, R. H. (2007). Whole grain phytochemicals and health. Journal of Cereal Science, 46(3), 732-737. http://dx.doi.org/10.1016/j. jcs.2007.06.010.

Liyana-Pathirana, C. M., \& Shahidi, F. (2006). Importance of insolublebound phenolics to antioxidant properties of wheat. Journal of Agricultural and Food Chemistry, 54(4), 1256-1264. http://dx.doi. org/10.1021/jf052556h. PMid:16478245.

Luo, X., Ma, X., Hu, H., Li, C., Cao, S., Huang, L., \& Chen, L. (2013). Kinetic study of pentosan solubility during heating and reacting processes of steam treatment of green bamboo. Bioresource Technology, 130, 769-776. http://dx.doi.org/10.1016/j.biortech.2012.12.088. PMid:23353588.

Mahmood, K., Alamri, M. S., Abdellatif, M. A., Hussain, S., \& Qasem, A A A. (2018). Wheat flour and gum cordia composite system: pasting, rheology and texture studies. Food Science and Technology, 38(4), 691-697. http://dx.doi.org/10.1590/fst.10717.

Manthey, F. A., \& Schorno, A. L. (2002). Physical and cooking quality of spaghetti made from whole wheat durum. Cereal Chemistry, 79(4), 504-510. http://dx.doi.org/10.1094/CCHEM.2002.79.4.504.

Mateo Anson, N., Robin, V. D. B., Havenaar, R., \& Haenen Guido, R. M. M. (2008). Ferulic acid from aleurone determines the antioxidant potency of wheat grain (Triticum aestivum $\mathrm{L}$ ). Journal of Agricultural and Food Chemistry, 56(14), 5589-5594. http://dx.doi.org/10.1021/ jf800445k. PMid:18558703.

Meyer, K. A., Kushi, L. H., Jacobs, D. R. Jr., Slavin, J., Sellers, T. A., \& Folsom, A. R. (2000). Carbohydrates, dietary fiber, and incident type 2 diabetes in older women. The American Journal of Clinical Nutrition, 71(4), 921-930. http://dx.doi.org/10.1093/ajcn/71.4.921. PMid:10731498.

Rosa-Sibakov, N., Poutanen, K., \& Micard, V. (2015). How does wheat grain, bran and aleurone structure impact their nutritional and technological properties? Trends in Food Science \& Technology, 41(2), 118-134. http://dx.doi.org/10.1016/j.tifs.2014.10.003.

Satou, K., Takahashi, Y., \& Yoshii, Y. (2010). Effect of superheated steam treatment on enzymes related to lipid oxidation of brown rice. Food Science and Technology Research, 16(1), 93-97. http:// dx.doi.org/10.3136/fstr.16.93.

Sehrawat, R., Nema, P. K., \& Kaur, B. P. (2016). Effect of superheated steam drying on properties of foodstuffs and kinetic modeling. Innovative Food Science \& Emerging Technologies, 34, 285-301. http://dx.doi.org/10.1016/j.ifset.2016.02.003.

Shi, Y. G. (2005). Soybean product technology. Beijing: China Light Industry Press. (In Chinese). 
Shin, H. Y., Ryu, J. H., Park, S. Y., \& Bae, S. Y. (2012). Thermal stability of fatty acids in subcritical water. Journal of Analytical and Applied Pyrolysis, 98, 250-253. http://dx.doi.org/10.1016/j.jaap.2012.08.003.

Smith, M. M., \& Hartley, R. D. (1983). Occurrence and nature of ferulic acid substitution of cell-wall polysaccharides in graminaceous plants. Carbohydrate Research, 118, 65-80. http://dx.doi.org/10.1016/00086215(83)88036-7.

Wang, L. J., Wang, L. B., Qiu, J., \& Li, Z. G. (2020). Effects of superheated steam processing on common buckwheat grains: lipase inactivation and its association with lipidomics profile during storage. Journal of Cereal Science, 95, 103057. http://dx.doi.org/10.1016/j.jcs.2020.103057.

Wu, J., Chen, J., Liu, W., Liu, C., Zhong, Y., Luo, D., Li, Z. Q., \& Huang, Z. L. (2014). Selective peroxidase inactivation of lightly milled rice by superheated steam. Journal of Cereal Science, 60(3), 623-630. http://dx.doi.org/10.1016/j.jcs.2014.07.005.

Wu, S. H., Guo, X. N., \& Zhu, K. X. (2020). Effect of superheated steam treatment on physicochemical properties of whole wheat flour. Journal of the Chinese Cereals and Oils Association, 10, 29-34. (In Chinese).
Wu, J., Mcclements, D. J., Chen, J., Liu, C., Luo, S., \& Liu, C. (2016). Improvement in storage stability of lightly milled rice using superheated steam processing. Journal of Cereal Science, 71, 130 137. http://dx.doi.org/10.1016/j.jcs.2016.08.006.

Xu, B., Wang, L. K., Miao, W. J., Wu, Q. F., Liu, Y. X., Sun, Y., \& Gao, C. (2016). Thermal versus microwave inactivation kinetics of lipase and lipoxygenase from wheat germ. Journal of Food Process Engineering, 39(3), 247-255. http://dx.doi.org/10.1111/jfpe.12216.

Xue, H. (2017). Effects of extrusion processing on the storage of extruded bran flour and research of technological parameters. Henan: Henan University of Technology. (in Chinese).

Zhang, F., Liu, F., Abbasi, A. M., Chang, X., \& Guo, X. (2019). Effect of steaming processing on phenolic profiles and cellular antioxidant activities of castanea mollissima. Molecules, 24(4), 703-716. http:// dx.doi.org/10.3390/molecules24040703. PMid:30781354.

Zhang, Q., Li, M., \& Li, H. (2020). Effects of different processing methods on dietary fiber composition and functional properties of highland barley. Food and Oils, 33(2), 91-94. (In Chinese). 